Acta Agroph., 2019, 26(2), 5-18

doi: $10.31545 /$ aagr/110097

\title{
SORPTION PROPERTIES OF SELECTED DIETARY FIBRES
}

\author{
Aneta Ocieczek $\mathbb{0}^{1}$, Halina Makała $\mathbb{\circledR}^{2}$ \\ ${ }^{1}$ Department of Commodity Science and Quality Management, Gdynia Maritime University \\ ul. Morska 81-87, 81-225 Gdynia, Poland \\ ${ }^{2}$ Division of Meat and Fat Technology, Institute of Agricultural and Food Biotechnology \\ ul. Jubilerska 4, 04-190 Warszawa, Poland \\ e-mail: a.ocieczek@wpit.umg.edu.pl
}

\begin{abstract}
A b stract: The aim of this study was to characterize and compare the water-binding and water -holding capacities of fibre preparations based on an evaluation of their adsorption properties. The scope of the work included the determination of the water content and activity in the tested material, the determination of adsorption isotherms at $20^{\circ} \mathrm{C}$, a mathematical description of sorption isotherms using the theoretical GAB sorption model as well as an estimation of the microstructural parameters of the tested fibre samples. The following commercial fibre preparations were examined: wheat - WF 200, WF 400, WF 600, potato - KF 200, apple - BJ, oats - BO and carrot - BM. The water content in the analysed fibre preparations

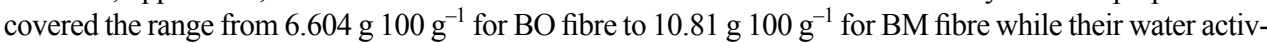
ity ranged between 0.495 for KF200 fibre and 0.564 for WF200 fibre. The fraction of free water present in carrot (BM) and potato (KF200) fibres was significantly more tightly bound to the product matrix than the fraction of free water in oats fibre (BO). Based on the studies conducted it was established that both the genetic variety and the technological process of micronization had an impact on the water-binding and holding capacities. This was proven on the basis of the evaluation of the adsorption properties and the differences in the surface microstructure of the preparations under examination. Not only the components present in the complex fraction of fibres, but also their physical state are of the utmost importance.

Keyw ords: fibre preparations, water-binding, water-holding capacities, adsorption properties
\end{abstract}

\section{INTRODUCTION}

An important element of a balanced diet that demonstrates pro-health effects on the human body is dietary fibre. The significant role of dietary fibre in human nutrition is unquestionable and conditioned by preventive action concerning diseases of the gastrointestinal tract, metabolic and cardiovascular system. At the same time, it should be emphasized that the functional, pro-health effect of fibre on the human body is conditioned by its ability to interact with water as expressed through water adsorption. 
The food industry has at its disposal a variety of dietary fibres derived, primarily from some cereals, fruit and vegetables, which are rich in metabolically inert carbohydrates. Due to their chemical composition, the dietary fibre preparations have varying functional properties and, as a consequence, different physiological effects. In addition to improving the health status of the consumer and lowering the energetic values of the product, dietary fibre inclusion into products has a favourable influence on their texture and consistency, is effective in emulsion formation, enhances water-binding capacity and thus inhibits the desiccation of foodstuffs as well as retarding the syneresis process (Bacers and Noll 1998, Boeckner et al. 2001, Franck 2002, Choi et al. 2009, Álvarez and Barbut 2013).

Dietary fibre preparations are characterized by a diverse water-binding capacity which is dependent on the product type, the technological process required to produce them, and the degree of micronization, which seems to play a key role in the formation of their useful properties, especially the texture of the enriched product (Sangnark and Noomhorm 2003, Sangnark and Noomhorm 2004, Lander 2004, Bacers and Noll 1998).

In recent years, studies have been undertaken into enriching the products with health-promoting components, including probiotics. The dietary fibre preparations of the new generation are distinguished by a neutral aroma and taste along with a high water-binding capacity and the distinct length and thickness of the fiberfibre filaments. Due to its chemical structure, the fibre can absorb water within its capillary system and distribute it throughout the volume of the product produced by the three-dimensional network. This network of fibre filaments is placed in the matrix of the finely ground batter. Besides its unquestionably useful properties, dietary fibre possesses healthy benefits, which are appreciated by health-conscious consumers (Sangnark and Noomhorm 2003, Zhuang et al. 2016).

Due to the growing shortage of fibre in products it would be advisable to enhance products, including meat products, with components that are not naturally present in their structure. Considering the existence of a wide range of dietary fibre preparations with very good technological and nutritional values at the disposal of the food industry, it is reasonable to use them for meet the needs of daily nutrient requirements (Makała, 2003, Makała and Olkiewicz 2004).

It is important to explore and compare the water-binding capacity of dietary fibre preparations in order to apply them correctly in real terms.

The present study was designed to determine the differences in the water-binding and holding capacities of fibre preparations based on their adsorption properties, which are in turn dependent on the product type and the micronization technology process. 


\section{MATERIAL AND METHODS}

The sampling material consisted of the following dietary fibre preparations: wheat - Vitacel ${ }^{\circledR}$ WF 200 , wheat - Vitacel ${ }^{\circledR}$ WF 400 , wheat - Vitacel ${ }^{\circledR}$ WF 600 (J. Rettenmaier \& Söhne GmbH+Co. KG, Germany), potato - KF 200 (POTEX, LYCKEBY STARKELSEN FOOD@FIBRE AB, Sweden), apple - BJ (Microfood Poland Sp. z o.o. Warsaw, Poland), oats - Vitacel ${ }^{\circledR}$ BO (J. Rettenmaier \& Söhne GmbH+Co. KG, Germany) and carrot-BM (LYCKEBY STARKELSEN FOOD@, FIBRE AB, Sweden). All preparations of wheat fibre (WF 200, WF 400, WF 600) were produced from the same raw material, which was subjected to a micronization process in order to diversify its performance (Tab. 1).

Table 1. Characteristics of the examined dietary wheat fibre preparations

\begin{tabular}{cccc}
\hline \multirow{2}{*}{ Product } & $\begin{array}{c}\text { Bulk density } \\
(\mathrm{g} / \mathrm{l})\end{array}$ & $\begin{array}{c}\text { Mean length of fibres } \\
(\mu \mathrm{m})\end{array}$ & $\begin{array}{c}\text { Water-binding capacity, } \\
\text { WBC } \\
(\%)\end{array}$ \\
\hline WF200 & 75 & 250 & 800 \\
WF400 & 40 & 500 & 1100 \\
WF600 & 210 & 80 & 550 \\
\hline
\end{tabular}

Source: materials from the manufacturer

The above-mentioned fibre preparations were derived from materials supplied by the manufacturers for experimental purposes.

All of the chemical substances used in the analysis and preparation of the saturated salt solutions were of analytical purity prior to the experiment.

The scope of the research included water content determination by oven drying at $105^{\circ} \mathrm{C}$ until a constant weight was reached (Krełowska-Kułas 1993).

The water activity was evaluated with an AquaLab water activity meter (Version AS4 2,14.0 2017, Series 4TE and 4TEV, Decagon Devices, Inc., Pullman, WA, USA) with an accuracy of $\pm 0.003 \mathrm{a}_{\mathrm{w}}$ at a temperature of $20^{\circ} \mathrm{C}$ (Zięba et al. 2019).

The sorption isotherms were plotted with a static-desiccator method. The equilibrium humidities were received for the examined materials and the atmosphere was regulated with the appropriate saturated solutions $\left(\mathrm{NaOH}, \mathrm{LiCl}, \mathrm{KC}_{2} \mathrm{H}_{3} \mathrm{O}_{2}, \mathrm{MgCl}_{2}\right.$, $\mathrm{K}_{2} \mathrm{CO}_{3}, \mathrm{Na}_{2} \mathrm{Cr}_{2} \mathrm{O}_{7}, \mathrm{KJ}, \mathrm{NaCl}, \mathrm{KCl}, \mathrm{KNO}_{3}, \mathrm{~K}_{2} \mathrm{Cr}_{2} \mathrm{O}_{7}$ ) were the basis for drawing the sorption isotherms (Tyszkiewicz 1987). The experiment comprised a water activity analysis of between 0.07 and 0.98 and was conducted at $293.15 \mathrm{~K}\left(20^{\circ} \mathrm{C}\right)$. The equilibration time lasted for 60 days and started with the placement of the samples in a desiccator. Thymol was placed in desiccators where the water activity was 0.7 and higher so that the samples could be protected against the development of microorganisms. In the first phase of the test, the individual $1 \mathrm{~g} \pm 0.1 \mathrm{mg}$ starch samples to be determined with a sorption isotherm were placed on weighing dishes with a diameter of $35 \mathrm{~mm}$ in such a manner that they were completely and evenly 
covered. Next, the dishes were incubated in a desiccator filled with $\mathrm{P}_{2} \mathrm{O}_{5}$ as a desiccant at ambient temperature for 3 weeks in order to limit the humidity $(\sim 2 \%)$ to a minimum. Following incubation, the weight of the samples was measured and they were placed in desiccators containing the appropriate salt solutions. Based on the initial weight of the samples (determined upon a 3-week period of incubation in a desiccator with $\mathrm{P}_{2} \mathrm{O}_{5}$ ) and the changes in water content, the water content equilibrium was determined and the adsorption isotherms were computed using an Excel spreadsheet. Prior to measuring the water activity in an AquaLab meter, the samples were incubated in a desiccator for 60 days (Ocieczek 2012). Isotherms were determined three times in each case three samples were subjected to the test. The differences between the mean values of the measurements and between successive repetitions were not statistically significant.

The differentiation of the sorption isotherm in the entire scope of $a_{w}$ was subjected to statistical analysis using Student's t-test of differences between medians for paired samples (Karpinski 2003).

The following GAB formula:

$$
v=\frac{V_{m} C K a_{w}}{\left(1-K a_{w}\right)\left(1-K a_{w}+C K a_{w}\right)}
$$

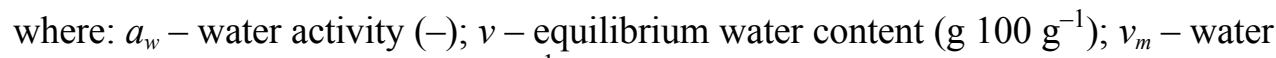
content in the multilayer $\left(\mathrm{g} 100 \mathrm{~g}^{-1}\right) ; C$ - Guggenheim energy constant; $K-$ a constant correcting the properties of the particles creating the multilayer in relation to the liquid phase (Figura and Teixeira 2007) was identified from the empirical data. The identification was performed using a non-linear regression and Monte Carlo algorithm. Such an approach helps to prevent the estimation process being halted by a local minimum. The minimization of the sum of the squared residuals was taken as a function. The computation was performed using an Excel 2010 spreadsheet. The researchers estimated the errors of the determined parameters of the GAB equation with the assistance of a SolverAid macroinstruction (Ocieczek 2012).

The specific surface area of adsorbent was calculated using the following equation:

$$
a_{s p}=\omega \frac{v_{m}}{M} N
$$

where: $a_{s p}$ - specific surface area of sorption $\left(\mathrm{m}^{2} \mathrm{~g}^{-1}\right) ; N$ - Avogadro's number $\left(6.023 \cdot 10^{23}\right.$ molecules $\left.\mathrm{mol}^{-1}\right) ; M$ - molecular mass of water $\left(18 \mathrm{~g} \mathrm{~mol}^{-1}\right) ; \omega-$ crosssectional area of water $\left(1.0510^{-19} \mathrm{~m}^{2}\right.$ molecule $\left.{ }^{-1}\right)$ (Pérez-Alonso et al. 2006).

The size and volume of the capillaries of the material studied were determined for the condensation area using the Kelvin equation and assuming that their shape was cylindrical. 


$$
\ln a_{w}=\omega \frac{-2 \sigma V}{r_{k} R T}
$$

where: $\sigma$ - surface tension of the liquid at temperature $\mathrm{T}\left(\mathrm{N} \mathrm{m}^{-1}\right) ; r_{k}$ - capillary radius $(\mathrm{nm}) ; R$ - universal gas constant $\left(\left(\mathrm{kJ}(\mathrm{mol} \mathrm{K})^{-1}\right) ; T\right.$ - process temperature $(\mathrm{K}) ; V$ - molar volume of adsorbate $\left(\mathrm{m}^{3} \mathrm{~mol}^{-1}\right)$ (Figura and Teixeira 2007).

\section{RESULTS AND DISCUSSION}

Plant fibres, consisting mainly of polysaccharides, are capable of absorbing considerable amounts of water and have a variety of functional properties depending on the degree of their solubility. (Robertson et al. 2000; Hemati Matin et al. 2013). Cereal grains are constituted predominantly offrom insoluble fibre. The outer layer of wheat is likely to contain up to $50 \%$ of plant fibres. Wheat bran contains mainly polysaccharides $(47 \%)$, i.e. cellulose and hemicellulose, proteins $(15 \%)$, starch $(8 \%)$, and minerals $(6 \%)$. Substances that incrust cellulose do not form chemical compounds with it, but are mechanically bound to it. (Stevenson et al. 2012).

Water is a food ingredient that is present in all its forms. Its presence in products determines all of the properties of food. Water affects both the nutritional and utility properties of food. Water activity plays a more important role in shaping food quality than its total content. Water activity is the result of not only the water content, but also the interaction between the body surface and the water, the phenomenon of the condensation of water vapour in the capillaries and the concentration and type of water-soluble substances. The initial content and activity of the water in the product is important for the further course of the surface phenomenon, because it determines its direction depending on the existing potential difference.

The water content of the tested fibre preparations ranged from $6.604{\mathrm{~g} 100 \mathrm{~g}^{-1}}^{-1}$

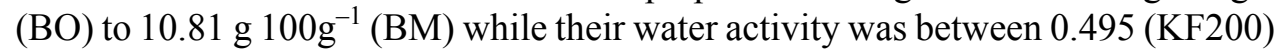
and 0.564 (WF200) (Tab. 2).

Table 2. The water content and water activity of the tested preparations of fibre

\begin{tabular}{lcc}
\hline Product & $\begin{array}{c}\text { Water content } \\
\left(\mathrm{g} 100 \mathrm{~g} \mathrm{~g}^{-1}\right)\end{array}$ & $\begin{array}{c}\text { Water activity } \\
(-)\end{array}$ \\
\hline WF200 & $7.472 \pm 0.014$ & $0.564 \pm 0.001$ \\
WF400 & $7.299 \pm 0.043$ & $0.547 \pm 0.003$ \\
WF600 & $7.313 \pm 0.086$ & $0.545 \pm 0.000$ \\
KF200 & $9.059 \pm 0.035$ & $0.495 \pm 0.001$ \\
BJ & $7.238 \pm 0.288$ & $0.498 \pm 0.004$ \\
BO & $6.604 \pm 0.033$ & $0.548 \pm 0.003$ \\
BM & $10.81 \pm 0.019$ & $0.536 \pm 0.000$ \\
\hline
\end{tabular}

The relationship between water content and water activity demonstrated that the fraction of free water present in carrot (BM) and potato (KF200) fibres is far more tightly bound to the product matrix than the fraction of free water in oat fibres 
(BO). It is theorized that this stronger water binding to the BM and KF200 matrices when compared to other fibre preparations might be due to a higher affinity of the molecules forming the fibre fraction to the water molecules (a larger number of hydrophilic functional groups). At the same time, it should also be emphasized that the binding of the free water fraction to the wheat fibre (WF) matrix reached similar values, irrespective of the micronization degree of the fibre molecules.

The source of much valuable information about the state of the water in the material are sorption isotherms. They illustrate the relationship between the amount of water adsorbed by a unit of mass of a food product and the activity of the water at a constant temperature and constant total pressure. This compound, characteristic for each product, may be presented in a graphical form or the mathematical parameters of models may be used for its description.

The adsorption properties of the studied fibre preparations were based on the curves of the adsorption isotherms describing the mechanism of water binding during its adsorption. The presented isotherms (Fig. 1) reflected the process of physical adsorption in porous bodies. The adsorption isotherms of water vapour for all fibre preparations showed the typical sigmoid shape of Type II according to BET classification. The course of the sigmoid curves of adsorption indicated that the observed phenomenon reflect the development of the polymolecular water layers on the surface of fibre preparations (Roman-Gutierrez et al. 2002; Limousin et al. 2007).

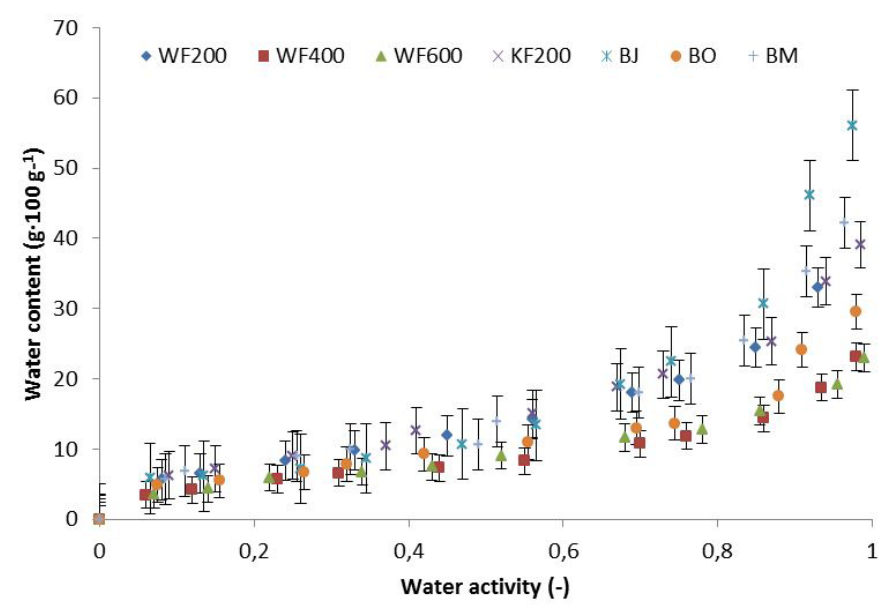

Fig. 1. The adsorption isotherms of the tested preparations of fibre

Based on a knowledge of the water sorption isotherms, and the sensitivity of the product to moisture, the degree of water adsorption may be determined as well as the changes that may occur in the material during storage. A knowledge of the shape of the sorption isotherm allows for the determination of the characteristic mechanism of water binding in the tested material. Water adsorption increased 
across all of the fibre preparations being tested in line with an increase in the $a_{w}$ value. The moisture uptake from the neighbouring space was conditioned by the presence of multimolecular substances in the tested fibre preparations which are capable of absorbing a considerable amount of moisture thanks to their abundant polar sites (groups - OH or -SH) (Ocieczek 2007).

Water sorption isotherms describing all of the tested fibre samples were characterized by a continuous course in the whole range of water activity. Thus, it may be assumed that during the water sorption process, there were no changes to the structure of the samples under consideration due to an increase in the orderliness of the individual components.

The preliminary assessment of water-binding and the holding capacities of the fibre preparations was performed by comparing their adsorption properties based on the mutual location of the isotherms in a monolayer $(0.00-0.20)$ and the capillary condensation (0.70-1.00). In the monomolecular layer the wheat fibres (WF400 and WF600) exhibiting varying degrees of micronization and oats fibres assumed the lowest values of adsorption capacity. Carrot fibre (BM), apple fibre (BJ) and wheat fibre (WF200) displayeddemonstrated intermediate results for adsorption capacity. Potato fibre (KF) demonstrated the highest adsorption capacity. When the water activity exceeded 0.70 , the absorption effect linked to water vapour adsorption by the surface of the examined fibre preparations was significantly distinctive. One may assume that above this water activity level, that capillary condensation occurred in the studied samples. With regard to capillary condensation, the interrelations between the sorption capacities of individual fibre preparations were not significantly modified. The wheat fibres (WF400 and WF600) and oats fibre (BO) had the lowest adsorption capacity. Intermediate values of adsorption capacity were reported for wheat fibre (WF200), carrot fibre (BM) and potato fibre (KF200). The highest values of adsorption capacity were determined for apple fibre (BJ). The shape and location of the adsorption isotherm for water vapour may differ depending on the type of products, their components, component affinity for water, their interactions and the active surface (Lewicki 1997; Blahovec 2004, Hyun-Wook et al. 2015). A drastic increase in the adsorption capacity of apple fibre (BJ) and an insignificant rise in the adsorption capacity of potato fibre (KF200) in the capillary condensation area when compared to the monolayer area may be associated with different kinds of interactions between the fibre molecules (KF200, BJ) and water, and as a consequence, this elicits changes in the structure of the fibre molecules. Through contact with water vapour, soluble fibres, i.e. pectins and natural resins, are subject to significant levels of hydration, thus forming a viscous and thick gel, whereas the insoluble fibres, i.e. cellulose, some hemicelluloses and lignin, remain in suspension and while swelling absorb water up to twenty times their mass (Stevenson et al. 2012). This interaction may alter the availability of the active 
sorption sites which is in accordance with the findings of many researchers (Areas and Cassiano 2001; Roman-Gutierrez et al. 2002; Makała and Ocieczek 2008). It may be assumed that once a significant amount of water has been absorbed, that the molecules of apple fibre (BJ) becoame loosened as a result of swelling, which was accompanied by the availability of new hydrophilic groups and a marked elevation in water adsorption. It may be assumed that unlike apple fibres, the molecules of the potato fibres (KF200), after absorbing a considerable amount of water, were packed in an ordered structure due to a crystallization-like process, which was concurrent with a partial loss of the availability of the functional groups and an insignificant increase in its adsorption capacity.

In order to establish the differentiation of the adsorption isotherm, a statistical analysis was conducted using the Student's t-test of differences for the paired samples and the results are illustrated in Table 3.

Table 3. Results of the Student's t-test of differences for the paired samples between equilibrium water contents

\begin{tabular}{llllllll}
\hline & WF200 & WF400 & WF600 & KF200 & BJ & BO & BM \\
\hline WF200 & & & & & & & \\
WF400 & $4.760 * * * *$ & & & & & \\
WF600 & $4.478^{* * *}$ & $3.485^{* * *}$ & & & & & \\
KF200 & $4.889 * * * *$ & $5.386 * * * *$ & $5.120 * * * *$ & & & \\
BJ & 1.703 & $3.089 * *$ & $2.920 * *$ & 1.319 & & \\
BO & $4.506 * * *$ & $4.905 * * * *$ & $3.858^{* * *}$ & $5.379 * * * *$ & $2.721 *$ & & \\
BM & 1.555 & $4.308 * * *$ & $4.058 * * *$ & 0.256 & 1.697 & $3.941 * * *$ & \\
\hline
\end{tabular}

$\mathrm{t}_{0.05}=2.228 ; \mathrm{t}_{0.02}=2.764 ; \mathrm{t}_{0.01}=3.169 ; \mathrm{t}_{0.001}=4.587 ; *_{-}$statistically significant difference at $0.05 ; *^{*}$ - statistically significant difference at $0.02 ; * * *$ - statistically significant difference at $0.01 ; * * * *$ - statistically significant difference at 0.001

An analysis of the results obtained showed no significant differences in the course of the adsorption isotherms of apple fibre (BJ), wheat fibre (WF200), potato fibre (KF200) and carrot fibre (BM) - which may be associated with similar water-binding and holding capacities of the surface in these preparations.

Water vapour sorption isotherms describing food are reflected in more than one sorption model. The criteria used to select the most appropriate sorption model are the degree of adjustment to the experimental data and the simplicity of the model. In order to compare the sorption properties of the fibre preparations, the following elements were evaluated: the mutual location of the adsorption isotherms at a temperature of $20^{\circ} \mathrm{C}$, the parameters of the adsorption isotherms determined on the basis of the GAB model, the characteristics of the selected microstructure parameters of the products under examination with the use of the Kelvin equation.

The sorption isotherms may be described by means of mathematical equations among which the GAB equation is of paramount importance as it takes into consideration the modified properties of the adsorbent in terms of multilayer adsorption (Timmermann et al. 2001, Timmermann 2003). The GAB model has many 
advantages over other models. This equation is considered to be the most useful sorption model in the study of food properties (Ocieczek and Palich 2004), as it justifies a theory of the sorption phenomenon (Blahovec and Yanniotis 2008) and, at the same time, its parameters are clearly defined (Caurie 2006) which allows for their correlation with the physical and chemical properties of the products (Mathlouthi 2001, Blahovec 2004).

Based on the course of the sorption isotherms over almost the entire $a_{w}$ range, the researchers determined the parameters of the GAB equation $\left(v_{m}, C, K\right)$ defining its adjustment (SSD - sum of the squared deviations) to empirical data and the calculated $a_{w}$ value corresponding to $v_{m}$. The findings obtained are given in Table 4 . The values of the SSD parameter (sum of the squared deviations) were in the range of 0.46-3.16 and demonstrate the suitable adjustment of the fitted equations in relation to the empirical data. The Hessian matrix was employed to evaluate the SSD value and to calculate the parameters of the GAB equation.

The GAB equation describes the empirical data well under the following conditions: $0.24<K \leq 1$ and $5.67<C \leq \infty$ defined by Lewicki (1997). The value of the $\mathrm{C}$ parameter is, according to Lewicki, an important determinant indicating the correctness of the choice of the GAB model to describe the empirical data. The value of the $\mathrm{K}$ parameter indicates the scope of the application of the GAB equation. These conditions were met in all variants of the experiment. The received values of the $\mathrm{K}$ and $\mathrm{C}$ parameters (Table 4) exhibit the appropriateness of its fit (PérezAlonso et al. 2006). For this reason, the estimation process was continued and the $v_{m}$ values together with the corresponding $a_{w}$ values were identified.

Table 4. Parameters of the GAB equation and aw corresponding to vm

\begin{tabular}{cccccc}
\hline Product & $S S D$ & $v_{m}$ & $a_{w}$ & $C$ & $\mathrm{~K}$ \\
\hline WF200 & $1.855 \pm 0.515$ & $7.697 \pm 0.181$ & 0.171 & $36.98 \pm 9.055$ & $0.823 \pm 0.006$ \\
WF400 & $1.339 \pm 0.437$ & $4.696 \pm 0.156$ & 0.153 & $49.72 \pm 20.02$ & $0.811 \pm 0.009$ \\
WF600 & $0.459 \pm 0.256$ & $5.320 \pm 0.108$ & 0.189 & $32.70 \pm 5.522$ & $0.784 \pm 0.006$ \\
KF200 & $1.890 \pm 0.520$ & $8.314 \pm 0.194$ & 0.169 & $40.09 \pm 9.623$ & $0.806 \pm 0.006$ \\
BJ & $13.16 \pm 1.375$ & $7.661 \pm 0.383$ & 0.208 & $19.65 \pm 9.455$ & $0.886 \pm 0.008$ \\
BO & $4.189 \pm 0.774$ & $5.475 \pm 0.240$ & 0.098 & $128.3 \pm 153.7$ & $0.830 \pm 0.010$ \\
BM & $1.983 \pm 0.532$ & $7.448 \pm 0.167$ & 0.151 & $46.89 \pm 13.86$ & $0.843 \pm 0.005$ \\
\hline
\end{tabular}

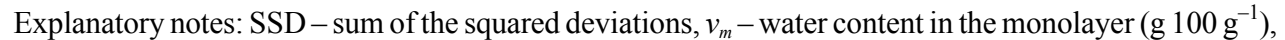
$a_{w}$ - water activity (-), $C$ - Guggenheim energy constant, $K$ - constant correcting properties of the multilayer molecules in relation to the liquid phase

The main advantage of the GAB model is that its parameters have a physical meaning in the interpretation of the sorption phenomenon. In addition, it allows for the study of the effect of temperature on isotherms using Arrhenius equations.

The monolayer capacity $\left(v_{m}\right)$ denotes the sorption capacity of the adsorbent and is used as an indicator of the availability of polar sites for water vapour. An insight into the concept of the monolayer allows for the analysis of various aspects of 
the physical and chemical spoilage of dry food products (Mathlouthi 2001). Karel (1975) found that the size of the monolayer of different food stuffs ranges from between 4 and $11 \mathrm{~kg} \mathrm{H}_{2} \mathrm{O}$ per $100 \mathrm{~kg}$ of dry mass. Potato fibre (KF200) had the highest capacity of monolayer whereas wheat fibre (WF400) had the lowest values. It should be noted that the capacity of the wheat fibre monolayer differed in relation to the degree of its micronization. It may be surmised that the $v_{m}$ capacity is dependent not only on the number of individual components rich in polar sites, but also on their physical state resulting from the degree of micronization (wheat fibre). For the cases being discussed here, it may be assumed that the shape of the locations of the isotherm of sorption were due to differences in the physical structure of the cellulose fibres (the lengths of the fibres were subject to shortening) caused by micronization.

For the examined fibre preparations, the values of the water activity corresponding to the monolayer ranged between 0.098 (BO) and 0.208 (BJ) and showed that water activity is a function not only of the water content but also of the interaction between the body surface and water, the condensation of water vapour in the capillaries, the concentration and type of substances dissolved in the water (Ocieczek, 2007), it is also dependent on the chemical composition and physical structure of the solid body matrix.

The $\mathrm{K}$ parameter is used to correct the properties of the water vapour molecules located in the multilayer adsorption as compared to the liquid phase. The values of the K parameter ranging from 0.784 to 0.886 confirmed that a fibre fraction played a key role in the formation of the sorption properties of the products tested. Pérez-Alonso et al. (2006) claimed that the values of the K coefficient ranging between 0.717 and 0.893 are characteristic of a product enriched with a considerable amount of fibre.

The values of the $\mathrm{C}$ constant for each sample examined were higher than 5.67 which confirmed that the sorption isotherms of the products tested were correctly classified as curves of type II (Lewicki 1997). The energy constant C reflected the difference between the enthalpy of desorption from the monolayer and the enthalpy of vaporization of the liquid adsorbent (Blahovec 2004). The enthalpy value of the physical adsorption process approximates $20 \mathrm{~kJ} \mathrm{~mol}^{-1}$. This insignificant change in enthalpy does not affect the identity of the physically adsorbed molecules. However, it should be taken into account that the presence of the surfaces may cause their deformation (Blahovec and Yanniotis 2008). In the process of chemical adsorption the molecules form chemical bonds with the surface. The chemisorption enthalpy is greater than that of physisorption. Its characteristic values average out at $200 \mathrm{~kJ} \mathrm{~mol}^{-1}$ (Mathlouthi 2001). The constant $\mathrm{C}$ values obtained led us to believe that in each given case a were witnessing a physical adsorption process was taking place. However, in order to be certain of the character of the phenomenon, spectroscopy examinations would be required. 
The microstructure of porous materials may be characterized on the basis of the sorption specific surface, the total capacity of the capillaries and the capillary radii which get filled upon the commencement of capillary condensation. The large sorption specific surface $\left(a_{s p}>500 \mathrm{~m}^{2} \mathrm{~g}^{-1}\right)$ points to the presence of narrow pores (there exists a reversed dependency between the specific surface and pore radii) whilst a small sorption specific surface $\left(a_{s p}<10 \mathrm{~m}^{2} \mathrm{~g}^{-1}\right)$ is characteristic of macro porous solid bodies (Pérez-Alonso et al. 2006). According to IUPAC classification, pores of $2-50 \mathrm{~nm}$ are labelled as mesoporous. Products, which are highly micronized and have a high porosity, are substantially hygroscopic, and as a result, water vapour adsorption may be very intensive.

The $v_{m}$ monolayer values determined from the GAB model were used to calculate the specific surface area of sorption. The sorption specific surface was calculated on the basis of $v_{m}$. The results obtained (Tab. 5) proved that potato fibre (KF200) has the largest specific surface.

Table 5. Structural characteristics of the tested products

\begin{tabular}{lccc}
\hline Product & $\begin{array}{c}\text { Sorption specific surface } \\
\left(\mathrm{m}^{2} \mathrm{~g}^{-1}\right)\end{array}$ & $\begin{array}{c}\text { Total capacity of } \\
\text { capillaries at aw }=0.70 \\
\left(\mathrm{~cm}^{3} 100 \mathrm{~g}^{-1}\right)\end{array}$ & $\begin{array}{c}\text { Size of capillaries at } \\
\text { aw }=0.70 \\
(\mathrm{~nm})\end{array}$ \\
\hline WF200 & 270.4 & 135.6 & 3.09 \\
WF400 & 165.0 & 79.46 & 1.85 \\
WF600 & 186.9 & 82.17 & 1.99 \\
KF200 & 292.1 & 138.2 & 3.25 \\
BJ & 269.2 & 173.6 & 3.39 \\
BO & 192.4 & 99.32 & 2.25 \\
BM & 261.7 & 141.2 & 3.10 \\
\hline
\end{tabular}

The data generated on the basis of the GAB model was also used to calculate the total capillary volume of the tested material as the sum of the water volume adsorbed by the material in the water activity range $0.70-0.93$ due to the ability of this model to describe sorption curves over a wide range. The most porous structure of the surface, which was manifested by the highest value of the total volume of capillaries, was characterized by apple fibre (BJ) (Tab. 5) while carrot fibre (BM), potato fibre (KF200) and wheat fibre (WF200) produced lower values of this parameter. Far lower values of the total capacity of the capillaries were found in oat fibre(BO), and wheat fibres (WF600) and (WF400).

Using the Kelvin equation, the characteristic capillary parameters were computed on the basis of adsorption isotherms for the purpose of describing capillary condensation (Tab. 5). This equation allows for the conversion of equilibrium relative pressures to the corresponding capillary radii.

It may be assumed that the calculated high value of the total capacity of the capillaries resulted from the capillaries of a greater radius being filled during the condensation process. This assumption is consistent with the obtained distribution in 
the sizes of the capillaries being filled at $a_{w}=0.7$. In individual fibre preparations this range was between $1.85 \mathrm{~nm}$ (WF400) and $3.39 \mathrm{~nm}$ (BJ). The obtained results indicated a mesocapillary characteristic in all of the fibre preparations under examination.

\section{CONCLUSIONS}

1. Preparations of dietary fibre, depending on the raw material from which they were made, differ in their ability to bind water, which is expressed in the capacity of the monolayer. Potato fibre is able to bind the largest amount of water, while wheat fibre (WF 400) binds the smallest amount.

2. The uninterrupted course of the sorption isotherms of all the tested dietary fibre products indicates the stability of their matrices, which, as a result of water adsorption in the form of vapour, did not undergo the process of crystallization.

3 . The phenomenon of water vapour adsorption on the surface of all of the tested dietary fibre preparations was physical, as indicated by the low values of the Guggenheim energy constant $C$.

4. The micronization of the dietary fibre particles differentiated their sorption properties as expressed by the size of the sorption surface and the surface and volume of the capillaries undergoing capillary condensation.

\section{REFERENCES}

Arêas E.P.G., Cassiano M.M., 2001. Folding interpenetration in a gliadin model: the role of the characteristic octapeptide motif. Biophys. Chem., 90, 135-146, https://doi.org/10.1016/S0301-4622 (01)00138-7

Álvarez D., Barbut S., 2013. Effect of inulin, $\beta$-Glucan and their mixtures on emulsion stability, color and textural parameters of cooked meat batters. Meat Sci., 94, 320-327, https://doi.org/10.1016/j. meatsci.2013.02.011

Bacers T., Noll B., 1998. Ballaststoffe halten Einzug in der Fleischverarbeitung. Fleischwirtsch., 78, 4, 316-320.

Blahovec J., 2004. Sorption isotherms in materials of biological origin mathematical and physical approach. J. Food Engine., 65, 489-495, https://doi.org/10.1016/j.jfoodeng.2004.02.012

Blahovec J., Yanniotis S., 2008. GAB Generalized Equation for Sorption Phenomena. Food Bioprocess Technol., 1, 82-90, https://doi.org/10.1007/s11947-007-0012-3

Boeckner, L.S., Schnepf, M.I., Tungland, B.C., 2001. Inulin: A review of nutritional and health implications. Adv. Food Nutr. Res., 43, 1-63, https://doi.org/10.1016/S1043-4526(01)43002-6

Caurie M., 2006. The derivation of the GAB adsorption equation from the BDDT adsorption theory. InternationalJ.FoodSci. Technol., 41,173-179, https://doi.org/10.1111/j.1365-2621.2005.01044.x

Choi Y.S., Choi J.H., Han D.J., Kim H.Y., Lee M.A., Kim H.W., 2009. Characteristics of low-fat meat emulsion systems with pork fat replaced by vegetable oils and rice bran fiber. Meat Sci., 82(2), 266-271, https://doi.org/10.1016/j.meatsci.2009.01.019

Figura L.O., Teixeira A.A. 2007. Food Physics. Physical Properties - Measurement and Applications. Springer Berlin Heidelberg New York, 
Franck, A., 2002. Technological functionality of inulin and oligofructose. The British J. Nutr., 87, 287-291, https://doi.org/10.1079/BJNBJN/2002550

Hemati Matin H.R., Shariatmadari F., Karimi Torshizi M.A., 2013. Various physico-chemical properties of dietary fibre sources of poultry diets. Int. J. Agricult. and Crop Sci., 6 (18), 1239-1245.

Huang S.C., Shiau C.Y., Liu T.E., Chu C.L., Hwang D.F., 2005. Effects of rice bran on sensory and physico-chemical properties of emulsified pork meatballs. Meat Sci., 70(4), 613-619, https://doi. org/10.1016/j.meatsci.2005.02.009

Hyun-Wook K., Yong Jae L., Yuan H. Brad Kim., 2015. Efficacy of pectin and insoluble fibre extracted from soy hulls as a functional non-meat ingredient. LWT - Food Sci. and Technl., 64, 10711077, https://doi.org/10.1016/j.lwt.2015.07.030

Karel M., 1975.Water activity and food preservation In: Physical principles of food preservation. Principles of food science. Part 2. (Eds M. Karel, O.R. Fennema, D.B. Lund). New York. Marcel Dekker, 237-263.

Krełowska-Kułas M., 1993. Test the quality of food products. PWE, Warszawa,

Lander S., 2004. Hochfuktionelle Weizenfasern. Fleischwirtschaft, 7, 45-47.

Lewicki P.P., 1997. The applicability of the GAB model to food water sorption isotherms. Int. J. Food Sci. and Technol., 32, 553-557, https://doi.org/10.1111/j.1365-2621.1997.tb02131.x

Limousin G., Gaudet J.-P., Charlet L., Szenknect S., Barthès V., Krimissa M., 2007. Sorption isotherms: A review on physical bases, modeling and measurement. Applied Geochem., 22, 249275, https://doi.org/10.1016/j.apgeochem.2006.09.010

Łomnicki A., 2006. Introduction to statistics for naturalists. PWN Scientific Publisher, Warszawa.

Makała H., 2003. Role of inulin in shaping of the quality of model meat product. Acta Agroph., 96, 2 (2), 347-357.

Makała H., Ocieczek A., 2008. Characteristics of sorption properties of the selected wheat cellulose preparations. Acta Agroph., 3(12), 747-766.

Makała H., Olkiewicz M., 2004. Role of the chosen wheat and oat cellulose preparations in binding of water in finely comminuted meat products. Acta Agroph., 110, (4)1, 85-96.

Mathlouthi M., 2001. Water content, water activity, water structure and the stability of foodstuffs, Food Control, 12, 409-417, https://doi.org/10.1016/S0956-7135(01)00032-9

Ocieczek A., 2007. Comparison of sorption properties of semolina and farina. Acta Agroph., 9, 1, 135-145.

Ocieczek A., 2012. Hydration properties of machine wheat flours as a discriminant of the usable quality. The scientific work of Gdynia Maritime University.

Ocieczek A., Palich P., 2004. Restrains in GAB equation for determining of absorbent structure, Acta Agroph., 4 (1), 115-122.

Pérez-Alonso C., Beristain C.I., Lobato-Calleros C., Rodríguez-Huezo M.E., Vernon-Carter E.J., 2006. Thermodynamic analysis of the sorption isotherms of pure and blended carbohydrate polymers. J. Food Engin. 77, 753-760, https://doi.org/10.1016/j.jfoodeng.2005.08.002

Robertson J.A., de Monredon F.D., Dysseler P., Guillon F., Amadò R., Thibault J.-F., 2000. Hydratation properties of dietary fibre and resistant starch: a European Collaborative Study. Lebensm.-Wiss. u.-Technol., 33, 72-79, https://doi.org/10.1006/fstl.1999.0595

Roman-Gutierrez A., Guilbert S., Cuq B., 2002. Distribution of water between wheat flour components: A dynamic water vapour adsorption study. J.Cereal Sci., 36, 347-355, https://doi.org/ 10.1006/jcrs.2002.0470

Sangnark, A., Noomhorm, A., 2003. Effect of particle sizes on functional properties of dietary fibre prepared from sugarcane bagasse. Food Chem., 80(2), 221-229, https://doi.org/10.1016/ S0308-8146(02)00257-1 
Sangnark A., Noomhorm A., 2004. Chemical, physical and baking properties of dietary fibre prepared from rice straw, Food Res. Int., 37, 66-74, https://doi.org/10.1016/j.foodres.2003.09.007

Stevenson L., Philips F., O'Sullivan K., Walton J., 2012. Wheat bran: its composition and benefits to health, a European perspective. Int. J. Food Sci. and Nutr., 63(8), 1001-1013, https://doi.org/10. 3109/09637486.2012.687366

Timmermann E.O., 2003. Multilayer sorption parameters: BET or GAB values? Colloids and Surface A: Physicochemical and Engineering Aspects, 220, 235-260, https://doi.org/10.1016/ S0927-7757(03)00059-1

Timmermann E.O., Chrife J., Iglesias H.A., 2001. Water sorption isotherms of foods and foodstuffs: BET or GAB parameters? J. Food Engin. 48, 19-31, https://doi.org/10.1016/S0260-8774(00)00139-4

Tyszkiewicz S., 1987. The water activity food products. Definition. The method of absolute measurement. Patterns. Przem. Spoż., 41, 2, 51-53.

Zhuang X., Han M., Kang Z., Wang K., Bai Y., Xu X., Zhou G., 2016. Effects of the sugarcane dietary fibre and pre-emulsified sesame oil on low-fat meat batter physicochemical property, texture, and microstructure. Meat Sci., 113, 107-115, https://doi.org/10.1016/j.meatsci.2015.11.007

Zięba M., Ocieczek A., Czerwonka D., 2019. Application of selected methods for evaluating the quality of powdery products as stability indicators of cosmetics in powder form on the example of dry shampoos. Polish J. Commodity Sci., 2 (59), 125-134. 